\section{G61(P) EFFICACY OF ANTIBIOTICS IN THE MANAGEMENT OF GRANULOMA ANNULARE IN CHILDREN: A SYSTEMATIC REVIEW OF THE LITERATURE}

${ }^{1} \mathrm{G}$ Chia, 'L Ahmed, ${ }^{2} \mathrm{P}$ Saroey, ${ }^{3} \mathrm{G}$ Oligbu. ${ }^{1}$ Department of Paediatrics, Northwick Park Hospital, London, UK; ${ }^{2}$ Paediatric Infectious Diseases, St George's Hospital, London, UK; ${ }^{3}$ Paediatric Infectious Disease Research Group, St George's University of London, London, UK

\subsection{6/archdischild-2018-rcpch.59}

Introduction Granuloma anulare (GA) is a benign inflammatory dermatosis of unknown cause. The Generalised granuloma annulare (GGA) is a subtype of which tends to be resistant to treatment. Various antibiotics have been proposed as a potential therapy for GGA, the most recent being combination therapy with Rifampicin, Ofloxacin and Minocycline (ROM).

Aims This study aim to explore the efficacy of antibiotics in treating GGA, and whether antibiotics may be useful in Children.

Methods We undertook a systematic review of English literature published from August 1947 to July 2017 to evaluate the efficacy of antibiotics in treating GGA and extract relevant data in children less than 18 years. Data sources included MEDLINE, EMBASE, Cochrane library, and references of identified articles.

Results We identified 790 potential studies, of which 229 were duplicates. 541 were excluded on the basis of title and abstracts. Of the 20 eligible studies included in the final analysis. Studies were from USA $(40 \%, \mathrm{n}=8)$, Europe $(35 \%, \mathrm{n}=7)$, Asia $(25 \%, n=5)$. Majority were case studies $(65 \%, n=13)$, case series $(10 \%, n=2)$, cohort studies $(10 \%, n=2)$ and Open label prospective studies $(15 \%, \mathrm{n}=3 ; 2$ on ROM therapy and 1 of dapsone). There were 113 treated patients, 60\% $(n=68)$ were female. Children constitute $14 \%(n=16 / 113)$, with age range 2-18 years, treated with antibiotics, of which 3 were GGA and 13 Non-GGA (i.e 8 Localised GA, 2 perforating GA, and 3 subcutaneous GA). Main antibiotic treatments reported were either the monthly combination therapy given as ROM, or single therapy of dapsone or doxycycline/Minocycline. There was a good response in Non-GGA in Children with only $15 \%$ recurrence rate while only $33 \%$ achieve remission in the GGA. Unlike adults, no side effects reported in Children.

Strength and limitations Our results highlight the strengths of combining outcomes of rare events. The lack randomised controlled trials, however, was a significant limitation. In addition, none of the literature looking at ROM combination therapy were in Children.

Conclusion There is paucity of evidence to support the use of antibiotics in the treatment of GGA in children. Although, recently ROM as shown promising results in adults, more studies are needed to validate this findings.

\section{REFERENCES}

1. Garg S, Baveja S. Monthly rifampicin, ofloxacin, and minocycline therapy for generalised and localised granuloma annulare. Indian I Dermatol Venereol Leprol 2015;81(1):35-39.

2. Simpson B, Foster $\mathrm{S}, \mathrm{Ku} J \mathrm{H}$, Simpson EL, Ehst BD. Triple antibiotic combination therapy may improve but not resolve granuloma annulare. Dermatologic Therapy 2014;27(6):343-347.

3. Mahmood T, Mansouri B, Menter A. Successful treatment of generalised granuloma annulare with adalimumab. Clin Exp Dermatol 2015:40(5):537-539.

4. Garg S, Baveja S. Generalised granuloma annulare treated with monthly rifampicin, ofloxacin, and minocycline combination therapy. Indian J Dermatol 2013;58 (3):197-199.
5. Successful treatment of recalcitrant disseminated granuloma annulare with minocycline, ofloxacin, and rifampin combination therapy. Journal of the American Academy of Dermatology 2013;68(4):AB64. http://dx.doi.org/10.1016/j. jaad.2012.12.268 Accessed 8/20/2017 3:18:52 PM.

6. Marcus DV, Mahmoud BH, Hamzavi IH. Granuloma annulare treated with rifampin, ofloxacin, and minocycline combination therapy. Arch Dermatol 2009;145 (7):787-789.

7. Steiner $A$, Pehamberger $H$, Wolff $K$. Sulfone treatment of granuloma annulare. Journal of the American Academy of Dermatology 1985;13(6):1004-1008. http:// dx.doi.org/10.1016/S0190-9622(85)70253-8 [Accessed: 8/19/2017, 11:06:43 AM]

8. Boyd AS. Granuloma annulare responsive to oral calcitriol. Int I Dermatol 2012;51(1):120-122.

9. Martín-Sáez E, Fernández-Guarino M, Carrillo-Gijón R, Muñoz-Zato E, Jaén-Olasolo P. Efficacy of dapsone in disseminated granuloma annulare: A case report and review of the literature. Actas Dermo-Sifiliográficas (English ed.) 2008:99 (1):64-68. http://dx.doi.org/10.1016/S1578-2190(08)70196-3 [Accessed: 8/16/ 2017 1:20:39 PM].

10. Gualco F, Zaccaria E, Drago F, Rebora A. Interstitial granuloma annulare and borreliosis: A new case. Journal of the European Academy of Dermatology and Venereology 2007;21(8):1117-1118.

11. Kiremitci U, Karagulle S, Topcu E, et al. Generalised granuloma annulare resolving to anetoderma. Dermatol Online J 2006:12(7):16.

12. Altomare GF, Frigerio E, Capella GL. Disseminated granuloma annulare: Effectiveness of sulphone treatment. G Ital Dermatol Venereol 2003;138(5):419-424.

13. Saied N, Schwartz RA, Estes SA. Treatment of generalised granuloma annulare with dapsone. Arch Dermatol 1980;116(12):1345-1346.

14. Cheng Y, Tsai W, Chuang F, et al. A retrospective analysis of 44 patients with granuloma annulare during an 11-year period from a tertiary medical centre in south Taiwan. Dermatologica Sinica 2016;34(3):121-125. Accessed 8/20/2017 3:19:30 PM. doi: http://dx.doi.org/10.1016/i.dsi.2015.11.002.

15. Yun JH, Lee JY, Kim MK, et al. Clinical and pathological features of generalised granuloma annulare with their correlation: A retrospective multicenter study in Korea. Ann Dermatol 2009;21(2):113-119.

16. Kozic $\mathrm{H}$, Webster GF. Treatment of widespread granuloma annulare with adalimumab: A case report. J Clin Aesthet Dermatol 2011;4(11):42-43.

17. Duarte A, Mota A, Pereira M, Baudrier T, Azevedo F. Generalised granuloma annulare: Response to doxycycline. Journal of the European Academy of Dermatology and Venereology 2009;23(1):84-85.

18. Kovich 0 , Burgin S. Generalised granuloma annulare. Dermatology Online Journal 2005;11(4).

19. Ashida M, Katayama I, Kamo T. Oral minocycline improved generalised granuloma annulare possibly triggered by spider-bite (arachnidism). Nishi Nihon Hifuka 2004;66(3):246-250.

20. Successful treatment of generalised granuloma annulare with amoxicillin/clavulanic acid. J Am Acad Dermatol 74(5):AB73.

\section{G62(P) RECOGNITION OF PAEDIATRIC ANAPHYLAXIS - AN AUDIT OF ALLERGY ADMISSIONS TO OUR EMERGENCY DEPARTMENT}

${ }^{1}$ KR Geddes, ${ }^{2} \mathrm{~N}$ Rao. ${ }^{1}$ Division of Medical Education, University of Manchester, Manchester, UK; ${ }^{2}$ Wythenshawe Hospital, Manchester University NHS Foundation Trust, Manchester, UK

\subsection{6/archdischild-2018-rcpch.60}

Background Anaphylaxis is uncommon but very serious. The recognition of anaphylaxis can vary with experience. Although the guidelines from the Resuscitation Council provide a useful framework for diagnosis, the criteria they give are very much open to interpretation. Therefore, there is a wide heterogeneity in recognition and management of anaphylaxis.

Aims and objectives We aimed to audit whether anaphylaxis in children is being correctly identified and managed, as well as the epidemiology of allergy and anaphylaxis, in children presenting to our emergency department (ED).

Methods Retrospective case notes audit of all paediatric attendances to our ED between the 1 st of April 2015 and the 31 st August 2016. The notes were screened and a total of 279 children were identified as having IgE mediated reactions. Audit standards were based on NICE (Quality standards 118) and Resuscitation council recommendations. 